\title{
Impact of Therapeutic Electrical Stimulation of Sacral Surface Considering Individual Anatomical Sacral Variations on Early Recovery Urinary Continence after Radical Prostatectomy
}

\author{
Naser A. ElSawy'1,2, Hesham G. Mahran³ , Abdullah G. Alkushi' \\ ${ }^{1}$ Department of Laboratory Medicine, Faculty of Applied Medical Sciences, Umm al Qura University, Makkah, KSA \\ ${ }^{2}$ Department of Anatomy and Embryology, Faculty of Medicine, Zagazig University, Zagazig, Egypt \\ ${ }^{3}$ Department of Physical Therapy for Surgery, Faculty of Physical Therapy, Cairo University, Cairo, Egypt \\ ${ }^{4}$ Department of Anatomy, Faculty of Medicine, Umm Al-Qura University, Makkah, KSA \\ Email: dr.alkushi@gmail.com
}

How to cite this paper: ElSawy, N.A., Mahran, H.G. and Alkushi, A.G. (2017) Impact of Therapeutic Electrical Stimulation of Sacral Surface Considering Individual Anatomical Sacral Variations on Early Recovery Urinary Continence after Radical Prostatectomy. Forensic Medicine and Anatomy Research, 5, 1-13.

http://dx.doi.org/10.4236/fmar.2017.51001

Received: October 15, 2016

Accepted: January 16, 2017

Published: January 19, 2017

Copyright $\odot 2017$ by authors and Scientific Research Publishing Inc. This work is licensed under the Creative Commons Attribution International License (CC BY 4.0).

http://creativecommons.org/licenses/by/4.0/

\begin{abstract}
Objectives: To investigate the effect of electrical stimulation of different anatomical variations of sacral surface on early recovery of urinary continence after radical prostatectomy. Methods: Twenty of 53 consecutive patients who underwent prostatectomy by a single surgeon were enrolled in this study. Ten patients were prospectively randomized to two groups; five patients in Sacral foramena stimulation group received postoperative surface electrical stimulation of sacral foramina area while five patients in control group did not received any electrical stimulation. Selection of remaining ten patients depended on sacral hiatus anatomical variations, assessed by plan X-rays. Of the ten patients, five patients with sacral hiatus subtotals were grouped under SHS1 while 5 patients with sacral hiatus totals were grouped as SHS2. Electrical stimulation for each group began 7 days after catheter removal, thrice a week for 8 weeks. Each of the 24 treatment sessions for each group composed of 20 minutes for sacral electrical stimulation. Continence was evaluated at baseline, 4 and 8 weeks using the 24-hour pad test and according to the incontinence section of the International Continence Society questionnaire. Results: After 2 weeks of treatment, the mean leakage weight was comparable between SFS group and SHS1 group while it was significantly lowered in SHS2 as compared to SFS and SHS1 groups. Comparing mean leakage weight at 8 weeks revealed further significant reduction in SHS2 group than in SFS and SHS1 groups. Moreover, percentage of continent patients was highest in SHS2
\end{abstract}


group after 8 weeks of treatment followed by SHS1, SFS and control respectively. Conclusions: Electrical stimulation of sacral hiatus surface area may provide better stimulation for sacral nerve than sacral foramena surface area and appears to be effective treatment for early recovery of urinary continence after radical prostatectomy.

\section{Keywords}

Urinary Incontinence, Electrical Stimulation, Sacral Foramina, Sacral Hiatus Area, Radical Prostatectomy

\section{Introduction}

Urinary incontinence (UI) or urine leakage remains the most common cause of morbidity after radical prostatectomy (RP) in men despite numerous progress made in the surgical techniques [1]. Persistent incontinence negatively affects the post-operative quality of life and is of more concern than erectile dysfunction, especially in older patients [2]. Peyromaure et al. reported that early UI affects $30 \%$ to $50 \%$ of patients from 3 weeks to 6 months after RP [3]. Post prostatectomy incontinence (PPI) is demonstrated widely, ranging from slight leakage with heavy lifting to continuous or gravitational leakage requiring multiple pads or even a penile clamp [4]. The etiology of PPI is multifactorial. Most cases of incontinence are a result of intra-operative damage to the native urinary sphincters, particularly the intrinsic sphincter component known as intrinsic sphincter deficiency. Besides, bladder denervation during prostatectomy is also a frequent cause of incontinence resulting in impaired detrusor contractility and poor bladder compliance [5] [6]. Prognostic factors for PPI include age, previous bladder surgery, nerve-sparing status, anastomotic stricture, and surgical experience [2] [7].

Numerous invasive and noninvasive treatment strategies are reported to manage PPI [8]-[15]. Noninvasive treatment predominantly includes physical exercise (i.e. biofeedback, pelvic floor or Kegel exercise) and neuromodulation (i.e. electrical and magnetic stimulations) while invasive treatment is mostly surgical (i.e. collagen injection, male sling and artificial urinary sphincter). Although surgical intervention is the treatment option for persistent and troublesome incontinence, it is typically delayed for at least one year following prostatectomy [15]. Within the first post-operative year of prostatectomy noninvasive methods are preferred. Pelvic floor muscle exercise (PFME) includes behavioral training to increase the strength of pelvic floor. However, the effectiveness of the PFME depends on its instruction method, and recent reports have suggested that the effectiveness would become higher by using the preoperative biofeedback method. Moreover, it can take several months to restore continence and some patients have persistent incontinence despite treatment [16].

Neuromodulation, using electrical or magnetic stimulation, was developed for urgency and stress incontinence [17]. Electrical stimulation (ES) has been used 
over several decades in the treatment of various lower urinary tract dysfunctions. Neuromodulation via ES using surface electrodes is the preferred method than implantable electrodes as the former is noninvasive and easy to administer [18]. Various sites for therapeutic application of ES have been studied to treat PPI. Pelvic floor electrical stimulation has been reported as a possible conservative treatment for UI after RP [19]. ES can artificially stimulate the pudendal nerve and its branches to cause direct and reflex responses of the urethral and periurethral striated muscles [9]. Another important and well-established stimulation site is that of the posterior tibial nerve [20]. The posterior tibial nerve is a mixed nerve containing L5 - S3 fibers, originating again from the same spinal segments as the parasympathetic innervations to the bladder (S2 - S4). In ES of sacral roots, the main sites for stimulations are S2 - S4 nerve roots which provide the principle motor supply to the bladder [21]. Specifically the S3 root mainly innervates the detrusor muscle and is the main target of sacral neuromodulation. It has been shown that SSTES has not only an inhibitory effect on detrusor over activity but also an efferent stimulant effect to the pudendal nerve as electrical stimulation to the skin on the posterior sacral foramens of the S2 and S4 was found to change bladder volume and intra-urethral pressure during stimulation [22]. However, the effectiveness of SSTES remains variable.

The anatomy of sacrum is variable from person to person [23]. Moreover, within the sacrum of a person various anatomical sites exist through which sacral nerves pass through such as sacral foramen and sacral hiatus. All the studies reported so far have applied the ES over surface of sacral foramen and investigated it effect in treating UI. None of the reports have studied the surface ES of sacral hiatus in managing UI. We therefore undertook this prospective randomized study to evaluate the effectiveness of SSTES for treating UI in post-RP patients taking into consideration the anatomical variations of sacrum. In this method, skin surface electrodes are applied on two anatomical areas of sacrum, sacral foramena area and sacral hiatus area, to provide stimulation.

\section{Materials and Methods}

\subsection{Population}

The subjects included a total of 53 consecutive patients who underwent standard RP at KasrEini Hospitals, Cairo University for clinically localized prostate cancer within December 2011 to December 2012. Exclusion criteria includes prior bladder or prostate surgery, prior urinary or fecal incontinence, neurogenic dysfunction, preoperative history of overactive bladder, psychiatric history or significant perioperative complications. None of these patients received radiotherapy after RP. None of the patient was prescribed anticholinergic drugs or other drugs able to influence urinary continence during the study. In all patients the catheter was removed 7 days after RP.

\subsection{Treatment}

From the 53 consecutive patients who underwent prostatectomy by a single sur- 
geon were enrolled in this study. Of them, 10 patients were prospectively randomized to two groups; SFS study groups (5 patients) and control group (5 patients).Patients in SFS group were included in an early sacral foramena surface area electrical stimulation. Patients in control group do not received any stimulation. The remaining 10 patient selection depended on sacral hiatus anatomical variations, assessed by plan X rays and were classified as SHS1 group (5 patients) and SHS2 group (5 patients). Patients in SHS1 group were included in an early sacral hiatus subtotals surface area electrical stimulation while patients in SHS2 group included electrical stimulation of early sacral hiatus totals surface area. All patients signed an informed consent before randomization. In SFS, SHS1 and SHS2 group the treatment began 7 days after catheter removal. This program was performed in all cases by the same therapist. Patients in study groups met the therapist thrice week for 8 weeks. Each of the 24 treatment sessions was homogeneously composed of sacral surface electrical stimulation 20 minutes a day. The Ethics Committee of the Cairo University approved this study.

\subsection{Patients Were Placed in Supine Position}

The stimulator, consisting of a pair of small adhesive electrodes was specially designed for this purpose (Nodoka, Lintec Co. Ltd., Tokyo, Japan). For SHS1 and SHS2 groups, the electrodes was placed symmetrically on the skin surface at hiatus area while for SFS group, it was placed symmetrically on the skin surface over the second through fourth posterior sacral foramens. The parameters of stimulators and duration of stimulation in both groups were fixed as follow; pulse of $30-\mathrm{Hz}$ frequency at $200-\mu$ s pulse width and maximal output voltage of $80 \mathrm{~V}$. All patients signed an informed consent before randomization. The Ethics Committee of the Cairo University approved this study.

Outcome Assessment during Estimation of PPI was performed after randomization at baseline i.e. 7 days after catheter removal, during follow-up at 4 weeks and 8 weeks after removing the catheter in all the four groups. Incontinence was objectively assessed using the 24-hour pad test and the number of pads used (primary outcome). Continence was defined as no pad use or a pad weight of $2 \mathrm{gm}$ or less gained during the test).Subjective evaluation (secondary outcome) was made using the incontinence section of the ICS-male questionnaire. Moreover, patients were asked to keep a voiding diary including the number of incontinence episodes, the number and volume of voids and the number of pads used.

\subsection{Statistical Analysis}

In this study, one way ANOVA was used to detect a difference in improvement rates and compare the variables among the four groups. Differences in the proportion of patients in the four groups who were continent at treatment intervals were estimated. Analysis of the risk factors for incontinence (age, prostate volume, nerve sparing technique) was performed and $p$ values less than 0.05 were considered statistically significant. All the analysis was performed using Statistical 
Package for the Social Sciences software, Version16 (SPSS Inc, Chicago, IL, USA).

\section{Results}

Patient characteristics are described in Table 1. A total of 20 cases were selected from 53 cases and were included in the evaluation. Ten patient selection from total cases depended on sacral hiatus anatomical variations, assessed by plan Xrays; 5 patients with sacral hiatus totalsSHS1, group (Figure 1) and 5 patients with sacral hiatus subtotals, SHS2 group (Figure 2), while the remaining 10 patients were prospectively randomized to two groups; SFS study groups as 5 patients received postoperative surface electrical stimulation of sacral foramina area (Figure 3, Figure 4) and control group, which did not received any electrical stimulation. The mean leakage weight was comparable within the groups at baseline (Figure 5). All the patients were evaluated for the entire treatment duration (8 weeks) and completed the electrical stimulation sessions. No complications were found in any patients and, in study groups, no patients complained of discomfort or irritation from surface electrical stimulation.

Four weeks of treatment significantly reduced the mean leakage weight in SHS2 group (36.2) compared to SHS1 (74), SFS (87.2) and control (114.4) groups. Moreover, the mean leakage weight of SHS1 and SFS groups were significantly lower when compared to control group although no difference between SFS and SHS1 was observed at 4 weeks (Figure 1, Table 1). Similar to 4 weeks of treatment, at 8 weeks the mean leakage weight was drastically reduced in SHS2 group compared to SHS1 (33.4), SFS (45.8) and control (97.2) group. Interestingly, within SHS2 group the mean leakage weight is reduced by approximately $80 \%$ at 8 weeks as compared to 4 weeks of treatment (7.4 vs. 36.2), in SHS1 it is lowered by approximately $55 \%$ (33.4 vs. 74 ) and in SFS group it is decreased by approximately $48 \%$ SFS ( 45.8 vs. 87.2 ) when compared to 4 weeks. In control group the reduction in mean leakage weight was however only $15 \%$ at 8 weeks compared to 4 weeks of treatment (Figure 2, Table 1).

The rate and time of continence achieved depends on patient age, prostate volume and nerve sparing procedure. No significant differences in patient's age, nerve sparring procedure and prostate volume were observed between the

Table 1. Demographic data and patients' characteristics related to spinal anesthesia $(\mathrm{P}=$ $0.001,0.002$, and 0.010 for mean arterial Spinal Anesthesia.

\begin{tabular}{ccc}
\hline & Group M & Group F \\
\hline Age (year) & $50.5 \pm 17.2$ & $49.9 \pm 17.8$ \\
Gender (M/F) & $300 / 25$ & $303 / 22$ \\
Weight (kg) & $65.9 \pm 12.8$ & $68.9 \pm 12.5$ \\
Height (cm) & $165.8 \pm 8.5$ & $168 \pm 8.8$ \\
ASA (I-II) & $125 / 200$ & $150 / 175$ \\
Duration of surgery (min) & $75.8 \pm 48.5$ & $78.5 \pm 50.8$ \\
\hline
\end{tabular}




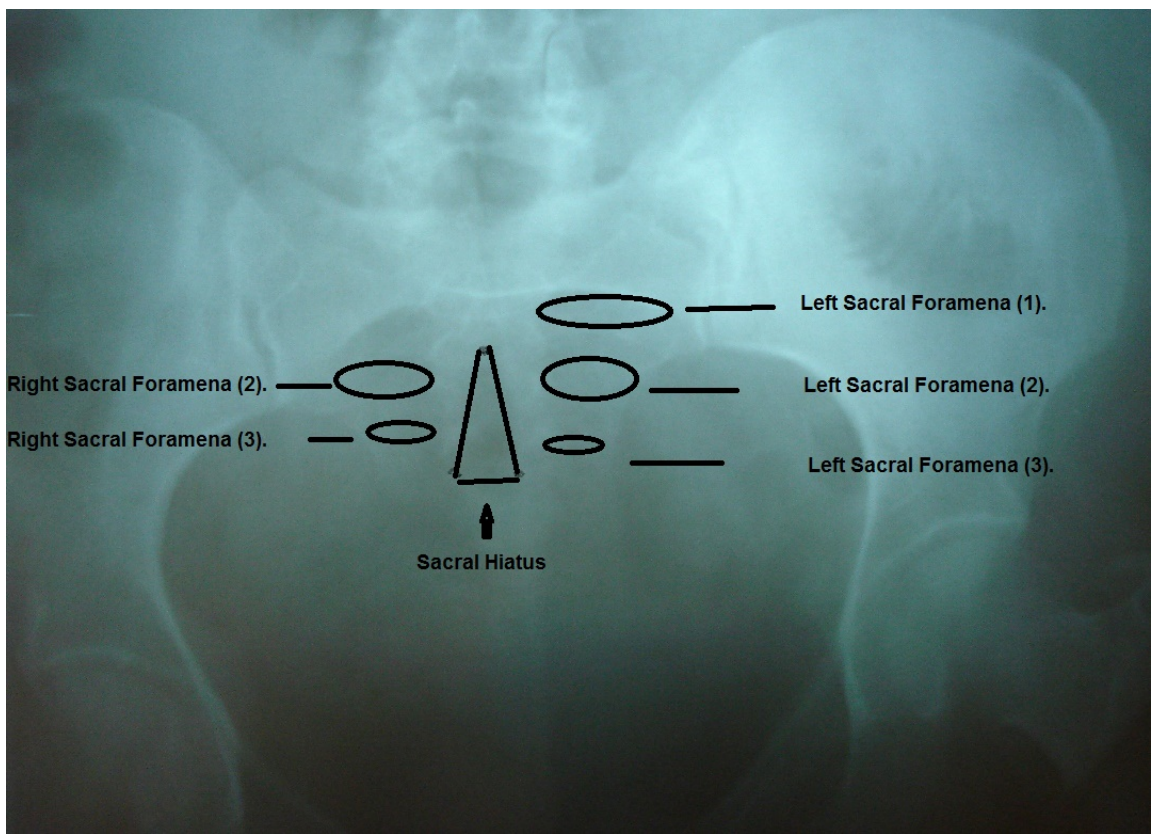

Figure 1. Anteroposterior view of male pelvic radiograph illustrating sacral hiatus with its apex at the level of S2 (arrow) and base at S3 (bar).

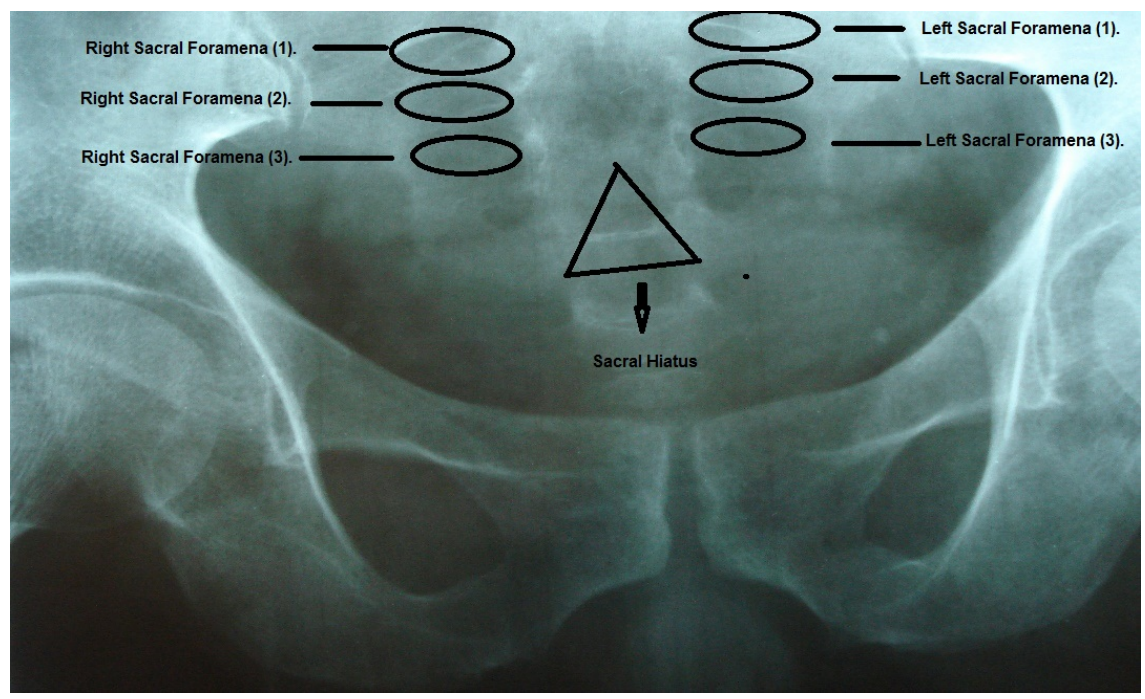

Figure 2. Anteroposterior view of male pelvic radiograph showing sacral hiatus with its apex at the level of S2 (arrow) and base at S4.

groups ( $\mathrm{p}>0.05$ ) (Figure 5). Subsequent to 8 weeks of treatment, 20\% (1 patient) in SHS2, 40\% (2 patients) in SHS1, 60\% (3 patients) in SFS and 80\% (4 patients) in control groups remained incontinent as analyzed by 24 -hr pad test data mentioned in ICS-questionnaire (Table 2). Hence, the objective continence at the end of the treatment (8 weeks) after randomization was $80 \%$ in SHS2, $60 \%$ in SHS1, $40 \%$ in SFS and $20 \%$ in control groups (Table 3, Figure 5). Together, these data suggest that ES of sacral nerves via sacral hiatus is more effective in treating early incontinence post-RP than sacral foramena (i.e., urine loss greater than $2 \mathrm{gm})$. Therefore, the objective continence rate 8 . 


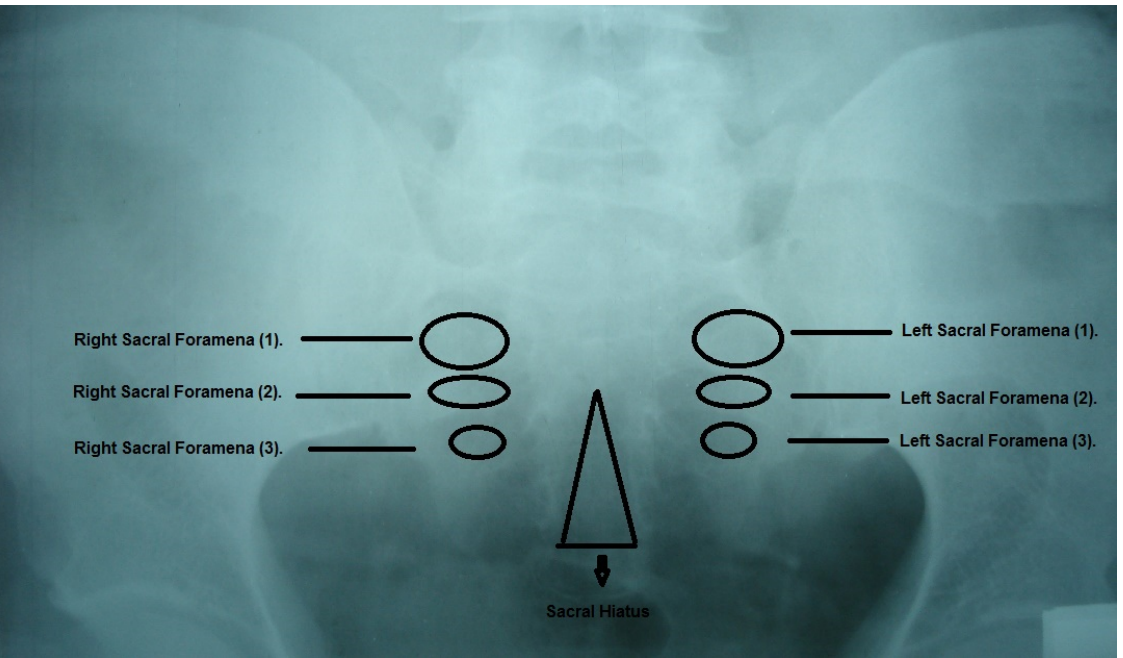

Figure 3. Anteroposterior view of male pelvic radiograph showing sacral hiatus subtotal with its apex at the level of S1 (arrow) and base at S3.

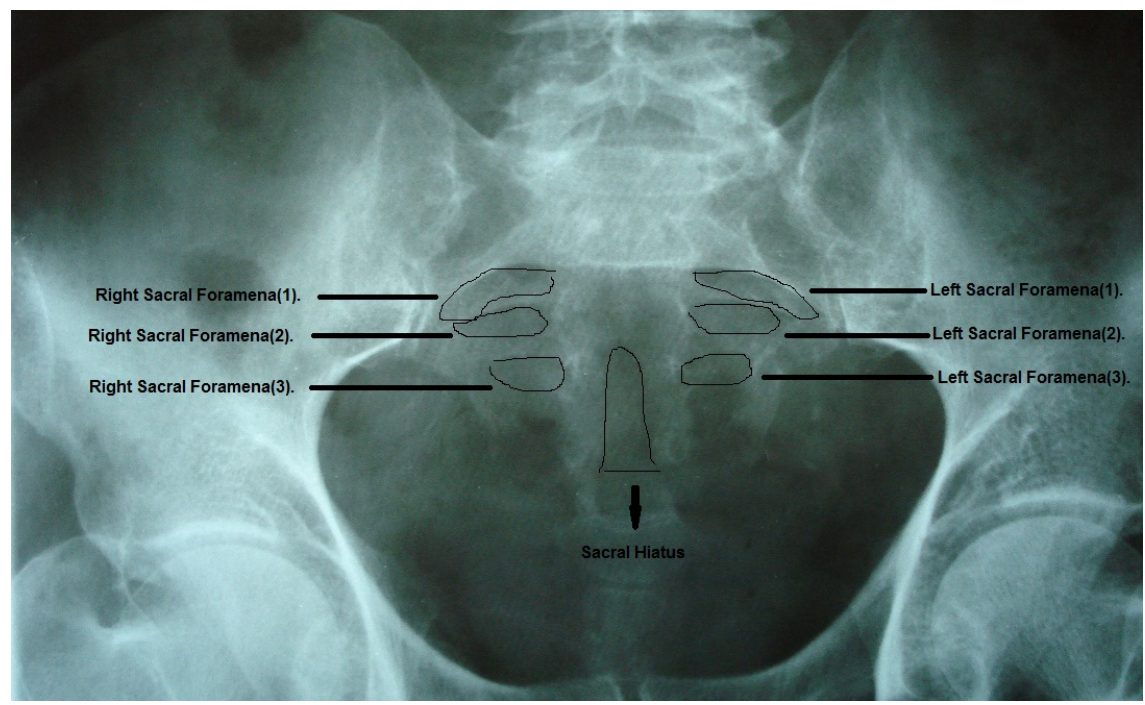

Figure 4. Anteroposterior view of male pelvic radiograph showing sacral hiatus total with its apex at the level of S1 (arrow) and base at S5.

\section{Discussion}

Compromised quality of life is the main drawback of PPI. Treatment regimen which causes early return of the continence in post-RP patients is desirable. We found that electrical stimulation of sacral nerves by surface stimulation has variant effect on the degree of continence achieved when applied at different anatomic sites in patients who had undergone radical prostatectomy by single surgeon. Urinary incontinence was lowest when therapeutic surface electrical stimulation was applied at sacral hiatus totals, followed by sacral hiatus subtotals and sacral foramina respectively compared with control patients who did not received any stimulation. Therefore, our results indicate that application of SSTES via sacral hiatus area as a promising approach to treat early UI in PPI patients.

Although numerous noninvasive procedures exist for treating PPI (PFME, 


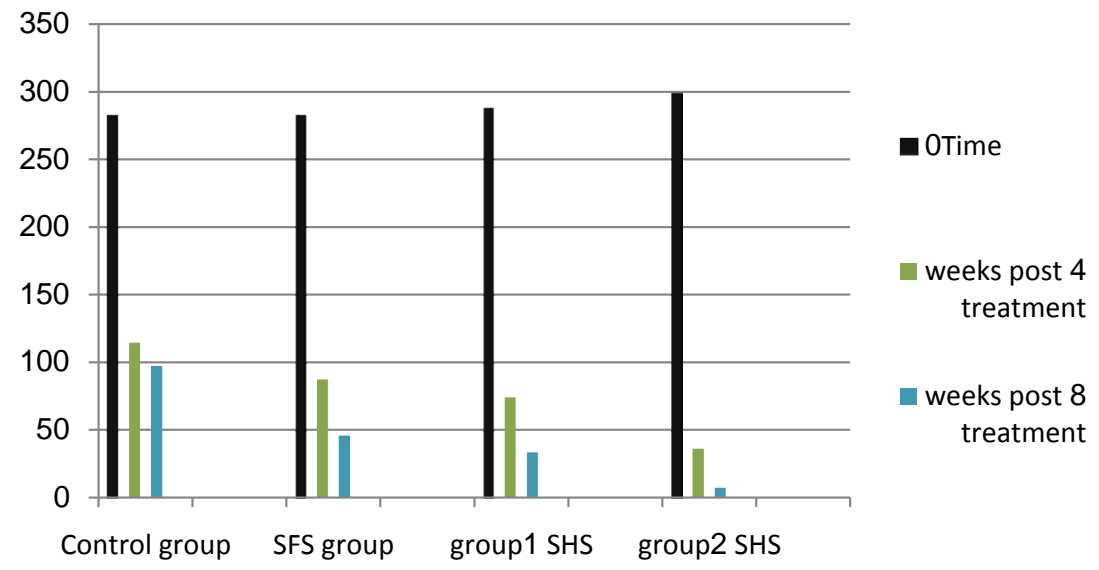

Figure 5. The difference of mean leakage weight between groups at different time of treatment shows the percent of continence in different groups at different time of treatment

Table 2. Incidences of Side Effects Values are number of patients (\%). Group M: meperidine group, Group F: Fentanyl group. ${ }^{\star} \mathrm{P}<0.001$, compared to Group M.

\begin{tabular}{ccc}
\hline & Group M (325) & Group F (325) \\
\hline Pruritus (n) & $3 \%(9)$ & $2 \%(6)$ \\
Nause (n) & $6.8 \%(22)$ & $5 \%(16)$ \\
Respiratory depression (n) & $0 \%(0)$ & $0 \%(0)$ \\
Seadation score (n, 2, 3, 4) & $300 / 20 / 5$ & $298 / 15 / 12$ \\
Bradicardia & $10 \%(32)$ & $12 \%(39)$ \\
\hline
\end{tabular}

Table 3. Number of patients and points of perioperatore shivering.

\begin{tabular}{ccc}
\hline & Group M & Group F \\
\hline 0 & $250^{\star}$ & 23 \\
1 & 60 & 85 \\
2 & 10 & 58 \\
3 & 3 & 35 \\
4 & 2 & 15 \\
\hline
\end{tabular}

${ }^{*} \mathrm{P}<0.001$ (Chi-square test).

biofeedback, neuromodulation by either magnetic or electrical stimulation), the beneficial effect of these methods in managing the UI is debatable [8]-[15]. Moreover, number of patients achieving continence by adopting different treatment regime was after a long time (6 months or more) post surgery, which would in turn affect the quality of life. Besides, the efficiency of treating UI was variable in all the studies which would be due to lack of standard and homogenous procedure and categorizing the patients. Sacral surface therapeutic electrical stimulation (SSTES) is a neuromodulation technique which has been used treat UI [18]. In RP patients, Nakagawa et al., reported that applying SSTES one day after surgery led to significantly larger mean void volume and significantly 
lower urine loss ratio as early as on day 3 as compared to control group which did not received any stimulation [24]. In another study, Morihiro et al., demonstrated that in laproscopic-RP patients application of SSTES combined with PFME showed higher continence percent as compared to only PFME group at 6 months (85\%vs 57\%) [25]. Interestingly, recovery rate of UI in SSTES group was $100 \%$ vs. only $64 \%$ in control at 12 months. Together, these studies concluded that SSTES is safe and an effective treatment for early recovery of UI after RP. However, one of the studies has analyzed the efficiency of the SSTES at a very early time point ( 3 days post-surgery) with no data for a longer time point, while in another study, the effect was analyzed at longer time point only (6 and 12 months). Furthermore, immediately post-surgery, urodynamic assessment of incontinence involves invasive procedures and doesn't correlate well with the subjective outcome. Rather, daily pad usage corresponds better with actual leakage than does the urine loss ratio daily pad usage corresponds better with actual leakage than does the urine loss ratio [8]. Therefore, we studied the effect of SSTES on mean leakage weight (24-hour pad test) and percent continent patients as early as 4 weeks ( 1 month) and 8 weeks ( 2 month) after catheter removal postRP.

Many studies have reported the efficacy of stimulating sacral nerves in treating UI arising due to various reasons [18] [24] [25] [26] [27]. Stimulation of sacral nerves by implanted electrodes has shown to be more efficient in treating incontinence than surface electrodes [18]. However, it is commonly associated with pain and post-operative infection. On account of the noninvasive nature and absence of pain or irritation, the surface electrodes are preferred over implanted electrodes. So far only two studies have reported the effect of SSTES in treating UI after RP [24] [25]. In both the studies SSTES electrodes were placed symmetrically on the skin surface over the second through fourth posterior sacral foramens. Surface electrical stimulation to the skin over sacral hiatus has not yet been investigated. Hence the current study investigated the effect of electrical stimulation of different anatomical areas of sacrum including sacral hiatus and sacral foramen on early recovery of urinary continence after RP. Sacral hiatus is the inverted U-shaped space opening at the inferior end of the sacral canal and is mainly of two types, sacral hiatus subtotals, where sacral hiatus open from S1 to S3 and sacral hiatus totals, where sacral hiatus open from S1 to S5. Normally, fifth sacral nerve passes though sacral hiatus. However, in some instances the due to lack of complete closure of S4, fourth sacral nerve can also pass though sacral hiatus [28]. This indicates that longer the length of sacral hiatus more the number of sacral nerves passing through it. Furthermore, sacral hiatus is covered only by skin, a subcutaneous fatty layer and the sacrococcygeal membrane [29]. Together these anatomical variations render sacral hiatus a favorable site for surface electrical stimulation. Our study is the first report of sacral nerve stimulation by placing the electrodes on skin over sacral hiatus. Furthermore, we also analyzed the effect of the anatomic variations on the sacral hiatus on the efficacy of sacral nerve stimulation. Interestingly, stimulation of sacral nerve via sacral 
hiatus was successful in lowering the incontinence to a larger degree compared to sacral foramen. Additionally, stimulating sacral nerve via sacral hiatus total was even more efficient in lowering the UI as compared to sacral hiatus subtotals. On the other hand, patient age, prostate volume, and nerve sparing had no significant impact on recovery rate.

Electrode location and stimulus intensity are important factors affecting sacral nerve stimulation. Takahashi et al., indicated that minute changes in electrode location caused considerable apparent changes of urethral pressure [30]. Furthermore, enough stimulation intensity is needed to obtain reliable effects of sacral nerve stimulation [18]. However, pain and irritation caused by higher stimulus intensity are considered the main flaws of the procedure. In our study, usage of X-rays for identifying the sacral hiatus anatomy/sacral foramena also aided in identifying there exact location. Moreover, throughout the study all the patients were uniformly subjected to surface electrical stimulation of pulse frequency $30-\mathrm{Hz}$ at $200-\mu$ s pulse width and maximal output voltage of $80 \mathrm{~V}$ for 20 minutes a day. This procedure was repeated thrice a week for 8 weeks. With this stimulus intensity we observed a significant gain of continence in all the three treatment groups. Besides, during the complete treatment session none of the patients complained about the pain or an irritation suggesting the stimulus intensity was effective enough to drastically reduce the UI without provoking any pain or irritation.

Nevertheless, present study has several constraints. In our study very few patients were enrolled. Moreover, our study is not controlled as it lacks the placebo effect. One of the disadvantages of the neuromodulatory approach is the short carry-over effect [24]. Our current study lacks the evaluation of long term effect of the treatment regimen in maintaining continence for which follow up of the patients is required. Moreover, the optimal duration of SSTES remains to be elucidated. Nevertheless, the results show the possible therapeutic role of SSTES in the early phase of recovery of urinary function following RP.

\section{Conclusion}

We investigated the effect of surface electrical stimulation on different anatomical variations of sacral surface on early recovery of urinary continence after RP. Sacral surface stimulation appears to be effective for early recovery of urinary continence after surgery. Specifically, sacral hiatus surface stimulation provides better sacral nerve stimulation as the continence level is much higher. Nonetheless, this way of stimulation is recommended only in patient with short hiatal crest (subtotal sacral hiatus) or with lost hiatal crest (total sacral hiatus) but in patient with complete hiatal crest, sacral foramena surface stimulation should be the treatment of choice. A randomized controlled trial with large study population is essential to confirm these results.

\section{References}

[1] Berghmans, B., Hendriks, E., Bernards, A., de Bie, R. and Omar, M.I. (2013) Electrical 
Stimulation with Non-Implanted Electrodes for Urinary Incontinence in Men. The Cochrane Database of Systematic Reviews, 6, CD001202.

[2] Kundu, S.D., Roehl, K.A., Eggener, S.E., Antenor, J.A., Han, M. and Catalona, W.J. (2004) Potency, Continence and Complications in 3,477 Consecutive Radical Retropubic Prostatectomies. The Journal of Urology, 172, 2227-2231. https://doi.org/10.1097/01.ju.0000145222.94455.73

[3] Peyromaure, M., Ravery, V. and Boccon-Gibod, L. (2002) The Management of Stress Urinary Incontinence after Radical Prostatectomy. BJU International, 90, 155-161. https://doi.org/10.1046/j.1464-410X.2002.02824.X

[4] Litwin, M.S., Hays, R.D., Fink, A., Ganz, P.A., Leake, B., Leach, G.E. and Brook, R.H. (1995) Quality-of-Life Outcomes in Men Treated for Localized Prostate Cancer. JAMA, 273, 129-135. https://doi.org/10.1001/jama.1995.03520260051032

[5] Yamanishi, T., Mizuno, T., Watanabe, M., Honda, M. and Yoshida, K. (2010) Randomized, Placebo Controlled Study of Electrical Stimulation with Pelvic Floor Muscle Training for Severe Urinary Incontinence after Radical Prostatectomy. The Journal of Urology, 184, 2007-2012. https://doi.org/10.1016/j.juro.2010.06.103

[6] Song, C., Doo, C.K., Hong, J.H., Choo, M.S., Kim, C.S. and Ahn, H. (2007) Relationship between the Integrity of the Pelvic Floor Muscles and Early Recovery of Continence after Radical Prostatectomy. The Journal of Urology, 178, 208-211. https://doi.org/10.1016/j.juro.2007.03.044

[7] Sacco, E., Prayer-Galetti, T., Pinto, F., Fracalanza, S., Betto, G., Pagano, F. and Artibani, W. (2006) Urinary Incontinence after Radical Prostatectomy: Incidence by Definition, Risk Factors and Temporal Trend in a Large Series with a Long-Term Follow-Up. BJU International, 97, 1234-1241. https://doi.org/10.1111/j.1464-410X.2006.06185.x

[8] Filocamo, M.T., Li Marzi, V., Del Popolo, G., Cecconi, F., Marzocco, M., Tosto, A. and Nicita, G. (2005) Effectiveness of Early Pelvic Floor Rehabilitation Treatment for Post-Prostatectomy Incontinence. European Urology, 48, 734-738. https://doi.org/10.1016/j.eururo.2005.06.004

[9] Moore, K.N., Griffiths, D. and Hughton, A. (1999) Urinary Incontinence after Radical Prostatectomy: A Randomized Controlled Trial Comparing Pelvic Muscle Exercises with or without Electrical Stimulation. BJU International, 83, 57-65. https://doi.org/10.1046/j.1464-410x.1999.00894.x

[10] Parekh, A.R., Feng, M.I., Kirages, D., Bremner, H., Kaswick, J. and Aboseif, S. (2003) The Role of Pelvic Floor Exercises on Post-Prostatectomy Incontinence. The Journal of Urology, 170, 130-133. https://doi.org/10.1097/01.ju.0000072900.82131.6f

[11] Floratos, D.L., Sonke, G.S., Rapidou, C.A., Alivizatos, G.J., Deliveliotis, C., Constantinides, C.A. and Theodorou, C. (2002) Biofeedback vs Verbal Feedback as Learning Tools for Pelvic Muscle Exercises in the Early Management of Urinary Incontinence after Radical Prostatectomy. BJU International, 89, 714-719. https://doi.org/10.1046/j.1464-410X.2002.02721.X

[12] Wille, S., Sobottka, A., Heidenreich, A. and Hofmann, R. (2003) Pelvic Floor Exercises, Electrical Stimulation and Biofeedback after Radical Prostatectomy: Results of A Prospective Randomized Trial. The Journal of Urology, 170, 490-493. https://doi.org/10.1097/01.ju.0000076141.33973.75

[13] Yokoyama, T., Nishiguchi, J., Watanabe, T., Nose, H., Nozaki, K., Fujita, O., Inoue, M. and Kumon, H. (2004) Comparative Study of Effects of Extracorporeal Magnetic Innervation versus Electrical Stimulation for Urinary Incontinence after Radical Prostatectomy. Urology, 63, 264-267. https://doi.org/10.1016/j.urology.2003.09.024 
[14] Yokoyama, T., Inoue, M., Fujita, O., Nozaki, K., Nose, H. and Kumon, H. (2005) Preliminary Results of the Effect of Extracorporeal Magnetic Stimulation on Urinary Incontinence after Radical Prostatectomy: A Pilot Study. Urologia Internationalis, 74, 224-228. https://doi.org/10.1159/000083553

[15] Singla, N., Singla, A.K. (2014) Post-Prostatectomy Incontinence: Etiology, Evaluation, and Management. Turkish Journal of Urology, 40, 1-8. https://doi.org/10.5152/tud.2014.222014

[16] Burgio, K.L., Goode, P.S., Urban, D.A., Umlauf, M.G., Locher, J.L., Bueschen, A. and Redden, D.T. (2006) Preoperative Biofeedback Assisted Behavioral Training to Decrease Post-Prostatectomy Incontinence: A Randomized, Controlled Trial. The Journal of Urology, 175, 196-201. https://doi.org/10.1016/S0022-5347(05)00047-9

[17] Yamanishi, T., Kamai, T. and Yoshida, K. (2008) Neuromodulation for the Treatment of Urinary Incontinence. International journal of Urology, 15, 665-672. https://doi.org/10.1111/j.1442-2042.2008.02080.x

[18] Yokozuka, M., Namima, T., Nakagawa, H., Ichie, M. and Handa, Y. (2004) Effects and Indications of Sacral Surface Therapeutic Electrical Stimulation in Refractory Urinary Incontinence. Clinical Rehabilitation, 18, 899-907. https://doi.org/10.1191/0269215504cr803oa

[19] Anderson, C.A., Omar, M.I., Campbell, S.E., Hunter, K.F., Cody, J.D. and Glazener, C.M. (2015) Conservative Management for Postprostatectomy Urinary Incontinence. The Cochrane Database of Systematic Reviews, 1, CD001843.

[20] Sucar-Romero, S., Escobar-del Barco, L., Rodriguez-Colorado, S. and Gorbea-Chavez V. (2014) [Posterior Tibial Nerve Stimulation for Pelvic Floor Dysfunction]. Ginecologia y Obstetricia de Mexico, 82, 535-546.

[21] Schmidt, R.A., Jonas, U., Oleson, K.A., Janknegt, R.A., Hassouna, M.M., Siegel, S.W. and van Kerrebroeck, P.E. (1999) Sacral Nerve Stimulation for Treatment of Refractory Urinary Urge Incontinence. Sacral Nerve Stimulation Study Group. The Journal of Urology, 162, 352-357. https://doi.org/10.1016/S0022-5347(05)68558-8

[22] Namima, T.K.Y. and Tanaka, S. (1999) Acute Effect of Sacral Surface Therapeutic Electrical Stimulation on the Lower Urinary Tract in Urinary Disturbance. Proceedings of the 4th Annual Conference of the International Functional Electrical Stimulation Society, Sendai, 23-27 August 1999, 235-238.

[23] Cheng, J.S. and Song, J.K. (2003) Anatomy of the Sacrum. Neurosurgical Focus, 15, E3. https://doi.org/10.3171/foc.2003.15.2.3

[24] Nakagawa, H., Kaiho, Y., Namiki, S., Ishidoya, S., Saito, S. and Arai, Y. (2010) Impact of Sacral Surface Therapeutic Electrical Stimulation on Early Recovery of Urinary Continence after Radical Retropubic Prostatectomy: A Pilot Study. Advances in Urology, 2010, Article ID: 102751. https://doi.org/10.1155/2010/102751

[25] Morihiro, N.M.I., Shinji, K., Kenichi, T., Kazumasa, M. and Shiro, B. (2011) Effectiveness of Sacral Surface Therapeutic Electrical Stimulation (SSTES) on Early Recovery of Urinary Inocntinence after Laproscopic Radical Prostatectomy: A Prospective Study. Neurology and Urodynamics, 30.

[26] Skeil, D. and Thorpe, A.C. (2001) Transcutaneous Electrical Nerve Stimulation in the Treatment of Neurological Patients with Urinary Symptoms. BJU International, 88, 899-908. https://doi.org/10.1046/j.1464-4096.2001.02422.x

[27] Soomro, N.A., Khadra, M.H., Robson, W. and Neal, D.E. (2001) A Crossover Randomized Trial of Transcutaneous Electrical Nerve Stimulation and Oxybutynin in Patients with Detrusor Instability. The Journal of Urology, 166, 146-149.

https://doi.org/10.1016/S0022-5347(05)66096-X 
[28] Preeti Goswami, Y.Y. and Chakradhar, V. (2014) Sacral Foramina: Anatomical Variations and Clinical Relevance in North Indians. European Journal of Academic Essays, 1, 29-33.

[29] Senoglu, N., Senoglu, M., Oksuz, H., Gumusalan, Y., Yuksel, K.Z., Zencirci, B., Ezberci, M. and Kizilkanat, E. (2005) Landmarks of the Sacral Hiatus for Caudal Epidural Block: An Anatomical Study. British Journal of Anaesthesia, 95, 692-695. https://doi.org/10.1093/bja/aei236

[30] Takahashi, K.N.T., Tanaka, S., et al. (2001) Effect of Sacral Surface Therapeutic Electrical Stimulation on the Lower Urinary Tract in Urinary Disturbance. Sogo Rehabiriteshon, 29, 851-858.

\section{Abbreviations}

UI: Urinary incontinence

RP: Radical prostatectomy

PPI: Post prostatectomy incontinence

ES: Electrical stimulation

PFME: Pelvic floor muscle exercise

SSTES: Sacral surface therapeutic electrical stimulation

ICS: International Continence Society

SHS1: Sacral hiatus subtotals stimulation

SHS2: Sacral hiatus total stimulation

SFS: Sacral foramena stimulation

Submit or recommend next manuscript to SCIRP and we will provide best service for you:

Accepting pre-submission inquiries through Email, Facebook, LinkedIn, Twitter, etc. A wide selection of journals (inclusive of 9 subjects, more than 200 journals)

Providing 24-hour high-quality service

User-friendly online submission system

Fair and swift peer-review system

Efficient typesetting and proofreading procedure

Display of the result of downloads and visits, as well as the number of cited articles

Maximum dissemination of your research work

Submit your manuscript at: http://papersubmission.scirp.org/

Or contact fmar@scirp.org 